\title{
Notes on authors
}

\begin{abstract}
Alan Warde is Professor of Sociology in the School of Social Sciences and Professorial Fellow of the Sustainable Consumption Institute at the University of Manchester. He is well known for his writing on topics of consumption, cultural capital, food and eating. He has written many books on similar and related topics. Works on similar topics to this book include: Consumption, Food and Taste: Culinary Antinomies and Commodity Culture (Sage, 1997); (with Martens) Eating Out: Social Differentiation, Consumption and Pleasure (Cambridge University Press, 2000); (with Kjaernes and Harvey) Trust in Food: An Institutional and Comparative Analysis (Palgrave, 2007); (with Bennett et al.) Culture, Class, Distinction (Routledge, 2009); The Practice of Eating (Polity, 2016); and Consumption: A Sociological Analysis (Palgrave, 2017).
\end{abstract}

Jessica Paddock is a Senior Lecturer in Sociology at the University of Bristol. Her research employs sociological approaches to explore the interaction of everyday life practices, natural resource use, food consumption and social differentiation in the context of environmental change. Her work involves interdisciplinary collaborations across the social and natural sciences, which are published in journals including Sociology, Journal of Peasant Studies, Journal of Rural Studies, Poetics, Appetite, Sustainability and Ecosystem Services. Jessica has a $\mathrm{PhD}$ in Sociology from the Cardiff University School of Social Sciences.

Jennifer Whillans is a Research Fellow at the University of Bristol. Her primary academic focus is time use research; specifically, she is interested in the timing of activities across the day and week and examines the temporal organisation of people and practices using both qualitative and advanced quantitative methods. Alongside her work on Eating Out, she is undertaking a research project, funded by the British Academy under their Postdoctoral Fellowship scheme, entitled '(De)synchronisation of 
People and Practices in Working Households: The Relationship between the Temporal Organisation of Employment and Eating in the UK'. She has published articles in Poetics, Appetite, Public Health, European Journal of Ageing, Time and Society and Leisure Studies. Jennifer has a $\mathrm{PhD}$ in Sociology from the University of Manchester. 